\title{
Use Of U200 Insulin Degludec (Tresiba) And Metformin In An Adolescent With Type-1 Diabetes-mellitus
}

\section{Ved Bhushan Arya, Philip Newland-Jones, Nicola Trevelyan}

\section{BACKGROUND}

* Insulin dose requirements are higher during puberty and in overweight/obese individuals with type 1 diabetes mellitus (T1DM) due to insulin resistance.

* Through meta-analysis metformin has been shown to be beneficial as adjunctive therapy in T1DM adults independent of body mass index (BMI).

* The large volumes of insulin required to administer higher insulin doses in insulin-resistant individuals have adverse effects on insulin absorption.

* Insulin degludec (Tresiba) U200 preparation allows lesser volume administration for the same dose.

\section{AIM}

To describe a 16-year-old girl with T1DM whose basal insulin requirement decreased markedly when switching to insulin degludec (Tresiba) U200 with the addition of metformin.

\section{CLINICAL CASE}

- The patient was diagnosed with T1DM at the age of 5 years. GAD and islet cell antibodies were positive. $\mathrm{HbA} 1 \mathrm{c}$ at diagnosis was $89 \mathrm{mmol} / \mathrm{mol}$.

* Initial management was with multiple daily insulin (MDI) injections. At age 9 years she switched to continuous subcutaneous insulin infusion (CSII).

* At age 15 years she chose to change back to MDI due to recurrent skin abscess formation, secondary to chronic staphylococcal aureus colonisation.

* The patient increased her basal insulin detemir (Levemir) doses from $0.6 \mathrm{U} / \mathrm{Kg} /$ day up to $1.9 \mathrm{U} / \mathrm{kg} /$ day over 8 months following the switch from CSII. The detemir was given in two divided doses. During this period $\mathrm{HbA} 1 \mathrm{c}$ increased slightly from 58 to 64 $\mathrm{mmol} / \mathrm{mol}$ and BMl increased from 23.4 to $24.8 \mathrm{~kg} /$ $\mathrm{m}^{2}$. There were no episodes of ketoacidosis.

* She was trialed on insulin degludec (Tresiba) U200 at $30 \%$ reduced dose $(1.3 \mathrm{U} / \mathrm{kg} /$ day $)$ with addition of modified release metformin.

* Over the first 4 weeks following switch, due to recurrent hypoglycaemia, her basal insulin requirement reduced further to $0.7 \mathrm{U} / \mathrm{kg} /$ day $(60 \%$ reduction in basal insulin dose). 5 months later her insulin requirement remains at $0.6 \mathrm{U} / \mathrm{kg} / \mathrm{day} ; \mathrm{HbA} 1 \mathrm{c}$ is $60 \mathrm{mmol} / \mathrm{mol}$ and her BMl is $25.9 \mathrm{~kg} / \mathrm{m}^{2}$.

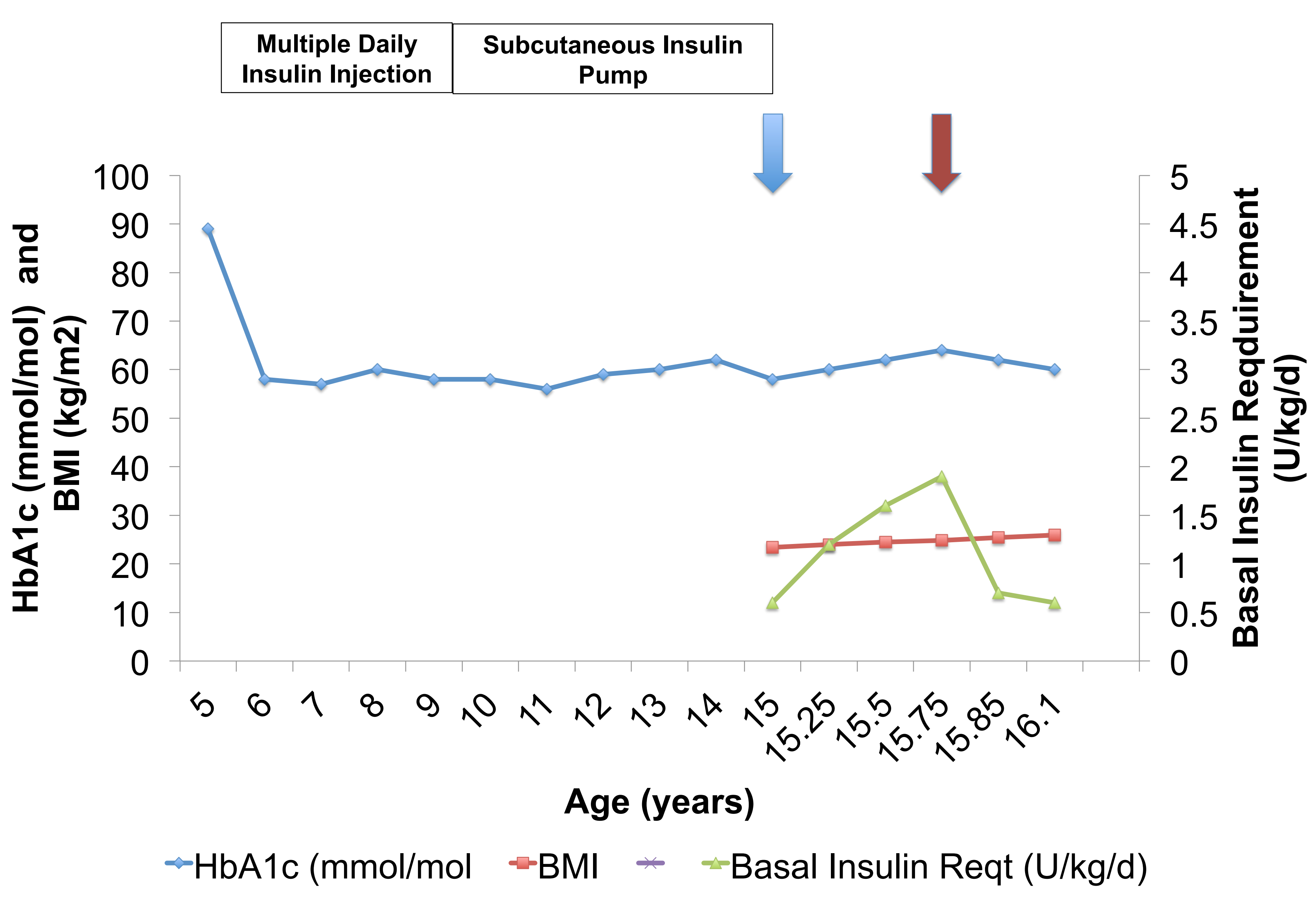

Figure 1: Graph showing $\mathrm{HbA} 1 \mathrm{c}$, body mass index (BMI), and Basal insulin requirement. Blue Arrow indicates initiation of MDI with Detemir as basal insulin. Red arrow indicates switching Detemir to Tresiba and initiation of Metformin

\section{CONCLUSIONS}

* Insulin degludec U200 preparation can be useful in T1DM patients requiring high basal insulin doses.

- Metformin is a useful adjuvant therapy in post pubertal T1DM patients with insulin resistance.

- Close monitoring is required over first weeks of therapy with insulin degludec (Tresiba) and metformin.

\section{REFERENCES}

1. Hamilton $\mathrm{J}$ et al. Metformin as an Adjunct Therapy in Adolescents With Type 1 Diabetes and Insulin Resistance. Diabetes Care 26:138-143, 2003.

2. Abdelghaffar $S$ et al. Metformin added to insulin therapy for type 1 diabetes mellitus in adolescents. Cochrane Database Syst Rev. 2009 Jan 21;(1).

3. Kusunoki $Y$ et al. Effects of Switching from Insulin Glargine or Detemir to Insulin Degludec in Patients with Type 1 Diabetes Mellitus. Diabetes Ther (2013) 4:461-472 